\title{
A prospective study on maternal near miss cases at a tertiary care hospital
}

\author{
Karuna Kanta Das, Sasindra Kumar Das*, Dhritimala Das
}

Department of Obstetrics and Gynecology, Gauhati Medical College and Hospital, Guwahati, Assam, India

Received: 05 November 2019

Accepted: 03 December 2019

\section{*Correspondence:}

Dr. Sasindra Kumar Das,

E-mail: sasindradas@yahoo.in

Copyright: (C) the author(s), publisher and licensee Medip Academy. This is an open-access article distributed under the terms of the Creative Commons Attribution Non-Commercial License, which permits unrestricted non-commercial use, distribution, and reproduction in any medium, provided the original work is properly cited.

\begin{abstract}
Background: Pregnant women's health status is not only reflected by mortality indicators alone hence the concept of Severe Acute Maternal Morbidity (SAMM) is appropriate for present health providing system. It helps to evaluate the quality of obstetric care in a particular institute. The main objectives of the study were to find a) Incidence of MNMM; b) Disorders underlying MNMM; c) Socio-demographic variables among MNMM; d) Facilities and skills needed to handle these near miss situations.

Methods: A prospective hospital-based study was conducted in the department of obstetrics and gynaecology, Gauhati Medical College and Hospital, Guwahati during the period $1^{\text {st }}$ June 2018 to $31^{\text {st }}$ May 2019. Cases were identified based on maternal near miss operational guidelines December 2014.

Results: Out of 16222 live births, 241 near miss cases were identified during the study. The maternal near miss incidence ratio is 14.86 per 1000 live births. The maternal near miss to maternal mortality ratio is 2.025. Most common cause of MNMM is hemorrhage (48.54\%) followed by hypertension (19.5\%), anemia (13.28\%), sepsis $(10.37 \%)$, cardiac dysfunction $(6.2 \%)$, liver dysfunction $(0.83 \%)$, renal dysfunction $(0.83 \%)$ and respiratory dysfunction $(0.41 \%)$.

Conclusions: The large magnitude of MNM cases may be attributed to improper management of obstetric emergencies at the referring hospitals, poor referral practices, inefficient transport system, limited availability of blood products and poor utilization of health care services at the peripheral hospitals. In our tertiary center, with the help of multidisciplinary action to all the near miss cases we can reduce maternal mortality to a great extent.
\end{abstract}

Keywords: Disorders, Hemorrhage, Hypertension, Maternal near miss

\section{INTRODUCTION}

According to millennium development goals (MDG) in 2015 , the goal number five was to improve the maternal health is much below our target. Our aim in reducing maternal mortality by $75 \%$ has not been met with MDG. ${ }^{1}$ Pregnant women's health status is not only reflected by mortality indicators alone hence the concept of severe acute maternal morbidity (SAMM) is appropriate for present health providing system. ${ }^{2,3}$ SAMM has been studied extensively in the recent past as an addition to the maternal mortality and also to evaluate the quality of obstetric care in a particular institute.

This concept is superior over maternal death in drawing attention to surviving women's reproductive health and lives and is equally applicable in developed countries. In developed countries, the maternal mortality has fallen to single digits whereas near miss cases are more and hence useful in evaluation of the present situation. Moreover, they have the advantage of not being as rare as maternal deaths for providing adequate information, as well as 
being rare enough not to overload the clinicians and data collection personnel within the facility.

According to World Health Organization (WHO), a maternal near miss case is defined as a women who nearly died but survived a complication that occurred during pregnancy, childbirth or within 42 days of termination of pregnancy. ${ }^{4}$ In practical terms women are considered near miss when they survive life threatening condition i.e. organ dysfunction.

\section{Aim}

- Incidence of MNMM

- Disorders underlying MNMM

- Socio-demographic variables among MNMM

- Facilities and skills needed to handle these near miss situations.

\section{METHODS}

Gauhati Medical College and Hospital, Guwahati is a tertiary care center where complicated cases from the neighboring districts are referred. A prospective hospitalbased study was conducted in the department of obstetrics and gynaecology, Gauhati Medical College and Hospital, Guwahati during the period $1^{\text {st }}$ June, 2018 to $31^{\text {st }}$ May 2019. A total of 241 cases were included in the study. Critically ill pregnant, laboring, post-partum and post abortable women who were admitted in Gauhati Medical College, Guwahati were studied.

\section{Inclusion criteria}

- In this study, Maternal Near Miss Operational Guidelines December 2014 was used for identification and inclusion of cases.

According to maternal near miss operational guidelines 2014, for diagnosis of near miss cases, the patient should meet minimum three criteria: one each from 1) clinical findings (either symptoms or signs), 2) investigations and 3) interventions done or any single criteria which signifies cardio-respiratory collapse.

It could be either 1.1 pregnancy specific obstetric and medical disorders which includes hemorrhage, sepsis, hypertension, postpartum collapse, liver dysfunction or cardiac dysfunction. 1.2 Preexisting disorders aggravated during pregnancy which includes anemia, respiratory dysfunction, cardiac dysfunction, respiratory dysfunction, hepatic dysfunction, endocrinal disorders like diabetic ketoacidosis or thyroid crisis, neurological dysfunction and renal dysfunction. 1.3 Incidental or accidental causes in pregnancy which includes accident, anaphylaxis, infections, embolism and infraction

\section{Exclusion criteria}

- Patients lost to follow-up
- Patients who leave hospital against medical advice.

\section{RESULTS}

The present study was conducted among all the high-risk maternal cases who presented to Gauhati Medical College and Hospital, Guwahati during the time period $1^{\text {st }}$ June 2018 to $31^{\text {st }}$ May 2019. The following results and observations were noted in this study:

- Total number of deliveries: 17155

- Total number of live-births: 16222

- Total number of Maternal Near Miss Cases: 241

- Total number of Maternal Mortality: 119

The maternal near miss incidence ratio is 14.86 per 1000 live births.

The maternal near miss to maternal mortality ratio is 2.025 .

Table 1 shows that out of the 241 near miss cases studied, $121(50.2 \%)$ cases belonged to the age group 18-24 years which forms about half of the population studied. 74 $(30.71 \%)$ cases belonged to 25-29 years group, 35 $(14.52 \%)$ cases in $30-34$ years group and $11(4.56 \%)$ cases in 35 years and above age group. Also, 211 $(87.55 \%)$ cases hailed from rural area whereas only 30 $(12.45 \%)$ cases came from urban area. 131 (54.35\%) cases belonged to Hindu, $97(40.25 \%)$ cases belonged to Islam and $13(5.39 \%)$ cases belonged to other religion. Besides that, $175(72.61 \%)$ cases are from the lower socioeconomic status. $59(24.48 \%)$ cases are from middle socio-economic status and $7(2.91 \%)$ cases belonged to upper socio-economic status. $163(67.63 \%)$ cases are literate and $78(32.37 \%)$ cases are illiterate.

Table 1: Distribution of patients according to sociodemographic variables.

\begin{tabular}{|c|c|c|c|}
\hline \multicolumn{2}{|c|}{ Characteristics } & No. of patients & $\%$ \\
\hline \multirow{4}{*}{$\begin{array}{l}\text { Age (in } \\
\text { years) }\end{array}$} & $18-24$ & 121 & $50.20 \%$ \\
\hline & $25-29$ & 74 & $30.71 \%$ \\
\hline & $30-34$ & 35 & $14.52 \%$ \\
\hline & 35 and above & 11 & $4.56 \%$ \\
\hline \multirow{2}{*}{$\begin{array}{l}\text { Residency } \\
\text { status }\end{array}$} & Rural & 211 & $87.55 \%$ \\
\hline & Urban & 30 & $12.45 \%$ \\
\hline \multirow{3}{*}{ Religion } & Hindu & 131 & $54.35 \%$ \\
\hline & Islam & 97 & $40.25 \%$ \\
\hline & Others & 13 & $5.39 \%$ \\
\hline \multirow{3}{*}{$\begin{array}{l}\text { Socio- } \\
\text { economic } \\
\text { class }\end{array}$} & Upper & 7 & $2.91 \%$ \\
\hline & Middle & 59 & $24.48 \%$ \\
\hline & Lower & 175 & $72.61 \%$ \\
\hline \multirow{2}{*}{$\begin{array}{l}\text { Literacy } \\
\text { status }\end{array}$} & Literate & 163 & $67.63 \%$ \\
\hline & Illiterate & 78 & $32.37 \%$ \\
\hline
\end{tabular}

Figure 1 shows that $81(33.61 \%)$ patients were primigravida. $108(44.4 \%)$ patients had one or two 
children, 45 (18.2\%) patients had three or four children and $7(2.9 \%)$ patients had five or more children.

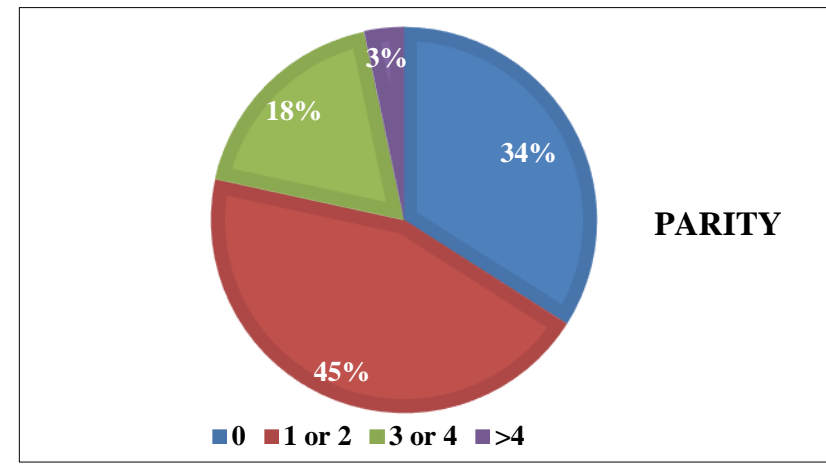

Figure 1: Distribution of near miss cases according to parity.

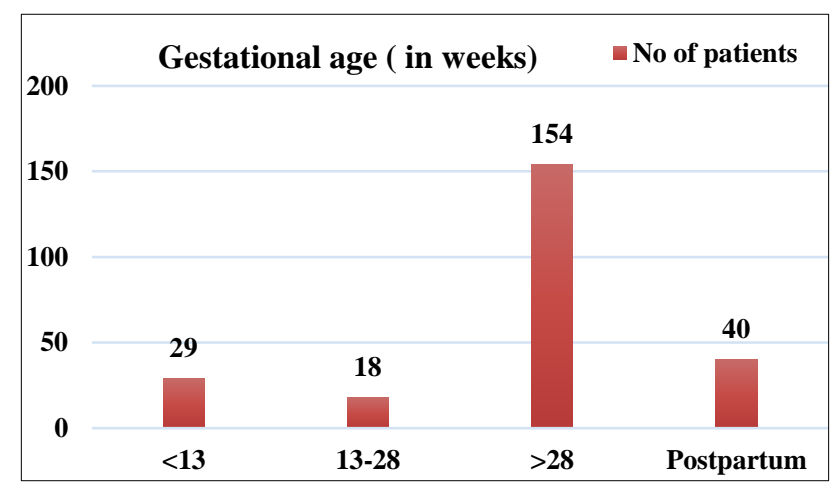

Figure 2: Distribution of near miss cases according to period of gestation.

Figure 2 depicts that patients whose gestational age is more than 28 weeks is $154(63.9 \%)$. Rest belonged to postpartum women where $40(16.6 \%)$ cases presented followed by less than 13 weeks where about 29 (12.03\%) patients presented and $18(7.47 \%)$ patients presented in 13-28 weeks.

Table 2: Distribution of cases according to antenatal check-ups and referral.

\begin{tabular}{|llll|}
\multirow{2}{*}{$\begin{array}{l}\text { Characteristics } \\
\text { Booking }\end{array}$} & Unbooked & 178 & $\%$ \\
\cline { 2 - 4 } status & Booked & 63 & $73.85 \%$ \\
\hline \multirow{2}{*}{ Referred } & Yes & 202 & $26.14 \%$ \\
\cline { 2 - 4 } & No & 39 & $83.82 \%$ \\
\hline
\end{tabular}

Table 2 depicts that $178(73.85 \%)$ patients had less than four antenatal check-ups and the rest, that is $63(26.14 \%)$ patients had four or more antenatal check-ups. Besides that, most of the near miss cases i.e. $202(83.82 \%)$ cases were referred from nearby places and only $39(16.18 \%)$ cases reported directly to this tertiary centre.

Table 3 shows that out of the 241 near miss cases, 117 $(48.54 \%)$ were due to hemorrhage followed by 47
(19.5\%) cases due to hypertension, $32(13.28 \%)$ cases due to anemia, $25(10.37 \%)$ cases due to sepsis, 15 $(6.2 \%)$ cases due to cardiac dysfunction, $2(0.83 \%)$ cases due to liver dysfunction, $2(0.83 \%)$ cases due to renal dysfunction and $1(0.41 \%)$ case due to respiratory dysfunction.

Table 3: Distribution of cases according to cause of near miss.

\begin{tabular}{|lcc|}
\hline Disorder & \multicolumn{1}{l}{ Number } & $\%$ \\
\hline \multicolumn{2}{l}{ Pregnancy specific } & obstetric and medical disorders \\
\hline Haemorrhage & 117 & $48.54 \%$ \\
\hline Sepsis & 25 & $10.37 \%$ \\
\hline Hypertension & 47 & $19.5 \%$ \\
\hline Liver dysfunction & 2 & $0.83 \%$ \\
\hline Cardiac dysfunction & 9 & $3.73 \%$ \\
\hline Pre-existing disorders aggravated during & pregnancy \\
\hline Anaemia & 32 & $13.28 \%$ \\
\hline Cardiac dysfunction & 6 & $2.48 \%$ \\
\hline Renal dysfunction & 2 & $0.83 \%$ \\
\hline Respiratory dysfunction & 1 & $0.41 \%$ \\
\hline
\end{tabular}

Table 4: Different interventions in Near miss cases.

\begin{tabular}{|lll|}
\hline Intervention & Number & $\%$ \\
\hline Vasoactive drugs & 107 & $45.23 \%$ \\
\hline Ventilatory support & 35 & $14.52 \%$ \\
\hline Laparotomy & 75 & $31.12 \%$ \\
\hline Evacuation & 30 & $12.44 \%$ \\
\hline Hysterectomy & 23 & $9.54 \%$ \\
\hline Dialysis & 2 & $0.83 \%$ \\
\hline Blood transfusion & 147 & $60.1 \%$ \\
\hline
\end{tabular}

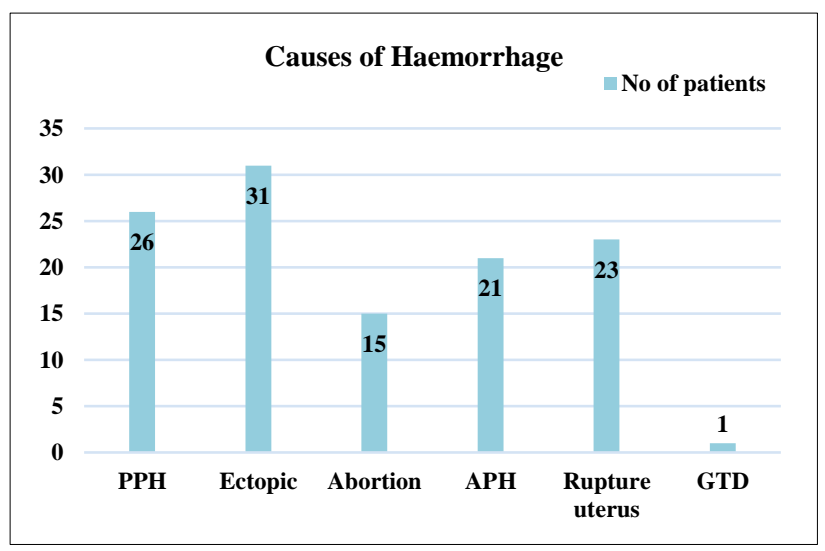

Figure 3: Causes of near miss according to hemorrhage.

Figure 3 shows that out of the 117 cases of hemorrhage, most of the cases were due to ectopic pregnancy $(26.5 \%)$ followed by $\mathrm{PPH}$, rupture uterus, APH, abortion and GTD.

Table 4 shows various interventions done to prevent maternal death. The most common intervention is blood 
transfusion which was received by $147(60.1 \%)$ of the patients. This was followed by use of cardiotonics or vasopressors in $107(45.23 \%)$ cases, laparotomy in 75 $(31.12 \%)$ cases, ventilator support in $35(14.52 \%)$ cases, evacuation of uterus in $30(12.44 \%)$ cases, hysterectomy in $23(9.54 \%)$ cases and dialysis in $2(0.83 \%)$ cases.

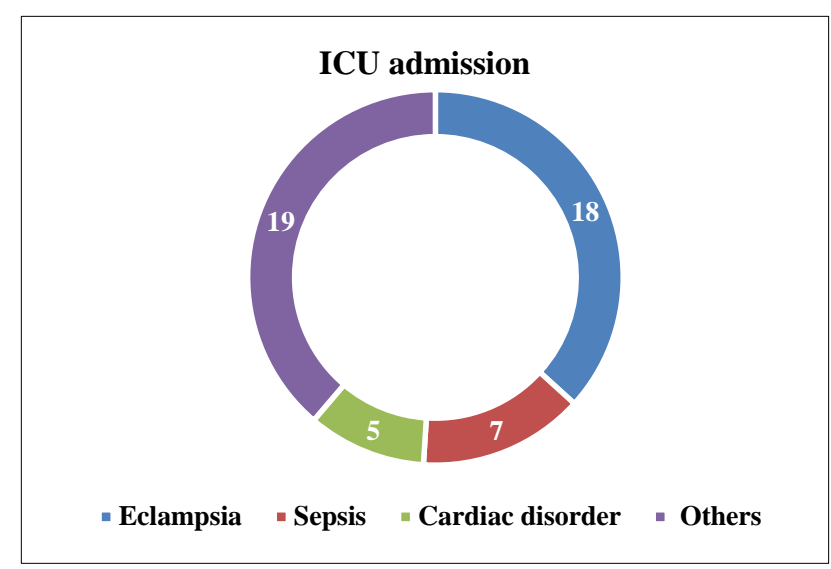

Figure 4: Distribution of different near miss cases according to ICU admission.

Figure 4 shows that, out of 241 near miss cases, 49 patients got admission in ICU. The most common reason of ICU admission was eclampsia which constitute 18 (36.73\%) patients of the near miss ICU admissions. This was followed by sepsis where $7(14.29 \%)$ patients and cardiac disorder where $5(10.21 \%)$ patients were admitted.

Thus, it can be seen that only $20.33 \%$ patients of the near miss cases got admission in ICU. The rest who have not got an ICU seat were managed in the high dependency unit (HDU) in our department.

\section{DISCUSSION}

This is the first attempt to document the maternal near miss cases in Guwahati, Assam. In our study, the maternal near miss incidence ratio is $14.86 / 1000$ live births. This is comparable with the studies conducted by Bansal $\mathrm{M}$ et al, Behera $\mathrm{R}$ et al, Kamal $\mathrm{S}$ et al, and Sahijwani DV et al. ${ }^{5-8}$ The maternal near miss incidence ratio in developing countries shows the same trend and vary between 15 to 40 per 1000 live births. The maternal near miss to mortality ratio in our study is $2.025: 1$ which is comparable to the studies mentioned above except Kamal et al, which have got a better ratio. ${ }^{7}$ If the ratio increases over time then we can say that our obstetric care has improved.

Most of the near miss cases belong to the age group of 18-24 years which coincides with the studies of Sharma P et al, and Bansal $\mathrm{M}$ et al. This is because most of the ladies in this part of the country get married of at an early age and also bears children early. ${ }^{5,9}$ Majority of the women were from rural areas $(87.55 \%)$ as there is lack of sufficient facilities in the health centres of the rural areas, thus most of the patients were coming to this tertiary hospital for seeking medical help whenever there is an obstetric emergency. This is in concordance with the study of Behera $\mathrm{R}$ et al, where $93 \%$ of the cases were from rural areas. ${ }^{6}$ Most $(72.61 \%)$ of the women belonged to lower socio-economic status which is in concordance with the studies of Behera $\mathrm{R}$ et al, and Sharma $\mathrm{P}$ et al. ${ }^{6,9}$ This is because our hospital is a government hospital and most of the women from poor socio-economic background come for treatment.

In present study it has been seen that, $160(66.39 \%)$ maternal near miss cases are multiparous. This is in concordance with Shrestha $\mathbf{J}$ et al, and Reena RP et al, where multiparous women have more association with the near incidence ratio. ${ }^{10,11}$ This is because multiparous women are not very anxious and they usually turn up late for investigation. Also, frequent child birth is one reason of poor health and subsequent development of near miss cases. It is also seen that most $(63.9 \%)$ of the near miss cases belonged to the third trimester and almost $80 \%$ of the cases cumulatively belongs to third trimester and postpartum period. This is comparable with the studies of Kamal $\mathrm{S}$ et al, Anuradha $\mathrm{J}$ et al, and Sharma $\mathrm{P}$ et al where most of the cases were either of the third trimester or postpartum period. . $^{7,9,12}$

In this study, it can be seen that most of the near miss cases have antenatal check-ups less than 4. This is in concordance with the studies conducted by Sharma $\mathrm{P}$ et al, Behera $\mathrm{R}$ et al, and Kamal $\mathrm{S}$ et al. ${ }^{6,7,9}$ The reason for few numbers of ANCs are lack of awareness and presence of household chores because of which the women barely meet the requisites of minimum 4 ANCs. We have seen that $83.82 \%$ of the near miss cases are referred. Whereas, in the studies of Kamal $\mathrm{S}$ et al and Behera $\mathrm{R}$ et al, have found a referral rate of $60 \%$ and $61.2 \%$ respectively. ${ }^{6,7}$ The higher percentage of referral cases in our hospital is due to the fact that it is only one tertiary centre catering a very large belt and the primary health centres in the nearby areas don't have sufficient facilities to deal with high risk pregnancies.

Haemorrhage is the most common cause accounting for $48.54 \%$ followed by hypertension in $19.5 \%$. This is in concordance with the studies conducted by Sujata P et al, Behera $\mathrm{R}$ et al, Kamal $\mathrm{S}$ et al and Anuradha $\mathrm{J}$ et al, where the two most common causes of near miss are haemorrhage and hypertension. ${ }^{6,7,12,13}$ Ectopic pregnancy is the most common cause of haemorrhage. This is due to the fact that PPH, abortion and APH are going down. The 3rd stage of labour is managed very properly, so the chance of PPH is less. Also rupture uterus which was most common cause seen in a few studies as mentioned above is the $3^{\text {rd }}$ most common cause of haemorrhage in our study as the number of grand multiparous women are less and post caesarean pregnancies are also cautiously monitored during labour. 
The most common intervention is blood transfusion $(60.1 \%)$ and most common surgical intervention is laparotomy $(31.12 \%)$ for ectopic pregnancy, rupture uterus and placenta previa. However, in studies by Behera $\mathrm{R}$ et al and Anuradha $\mathrm{J}$ et al, the most common intervention is use of vasoactive drugs and the most common surgical intervention is laparotomy. ${ }^{6,12} \mathrm{We}$ have seen that in our study, blood transfusion is more common than use of vasoactive drugs because the blood bank facilities of GMCH are good like 24 hours blood availability.

The number of ICU admissions is quite less in comparison to Kamal S et al and Sujata $\mathrm{P}$ et al., ${ }^{73}$ This is due to the fact that the number of ICU beds in the hospital is quite less and there is no separate obstetric ICU. So, we have to manage the patients in the high dependency unit in the department of obstetrics and gynaecology.

\section{CONCLUSION}

Near miss cases share many characteristics with maternal deaths and can directly inform about obstacles that had to be overcome after the acute onset of complications. To improve maternal and perinatal health scenario, women should be counselled about the importance of ANCs, health education of the society as well as improvement in socio-economic status, which are of utmost importance to reduce maternal mortality and morbidity.

The large magnitude of MNM cases may be attributed to improper management of obstetric emergencies at the referring hospitals, poor referral practices, inefficient transport system, limited availability of blood products and poor utilization of health care services at the peripheral hospitals. Thus, if corrective measures are taken for the above-mentioned problems, then maternal outcome can be greatly improved by reducing the maternal near miss cases. Besides that, in our tertiary center, with the help of multidisciplinary action and providing ICU care to all the near miss cases we can reduce maternal mortality to a great extent.

Though there is need for more research on severe maternal morbidity to validate these findings but a physician can definitely use these results to make some changes in the system for better management of the patients.

Funding: No funding sources Conflict of interest: None declared

Ethical approval: The study was approved by the Institutional Ethics Committee

\section{REFERENCES}

1. Nielsen HS, Eggebo TM. Millenium development goal 5- an obstetric challenge. Acta Obstetricia et Gynecologica Scandinavia. 2012;91(9):1007-8.

2. Stones W, Lim W, Al-Azzawi F, Kelly M. An investigation of maternal morbidity with identification of life threatening "near miss" episodes. Health Trends. 1991;23(1):13-5.

3. Sivalingum N, Looi KW. Clinical experiences with management of near miss cases in Obstet Med $\mathbf{J}$ Malaysia. 1999;54(4):496-503.

4. World Health Organization- Evaluating the quality of care for severe pregnancy complications: The WHO near miss approach for maternal health. WHO; 2011.

5. Bansal M, Lagoo J, Pujari K. Study of near miss cases in obstetrics and maternal mortality in Bastar, Chhattisgarh, India. Int J Repro Contracept Obstet Gynaecol. 2016;5(3):620-3.

6. Behera R, Behera AA. Study on maternal mortality and near miss cases. J. Evid Based Med Healthc. 2017;4(93):5720-4.

7. Kamal S, Roy $\mathrm{P}$ Singh S, Minz J. A study on maternal near cases at tertiary medical college, Jharkhand, India. Int J Repro Contracept Obstet Gynaecol. 2017;6:2375-80.

8. Sahijwani DV, Desai A, Kansara V. Analysis of near miss cases as a reflection of emergency obstetric services and need of obstetric ICCU. J South Asian Feder Obst Gynae. 2013;5(3):99-101.

9. Sharma P, Jaiswal A. A critical analysis of determinants of maternal near cases at rural tertiary health centre. Global J Res Analy. 2017;6(2):22778160 .

10. Shrestha J, Shrestha R, Tuladhar R, Gurung S, Shrestha A. Maternal near miss in a tertiary care teaching hospital. Am J Pub Health Res. 2015;3(5):17-22.

11. Reena RP, Radha KR. Factors associated with maternal near miss: a study from Kerala. Indian J Pub Health. 2018;62:58-60.

12. Anuradha J, Srinivas PJ, Manjubhashini S. A prospective study on maternal near miss cases in a tertiary care hospital in Vishakhapatnam. IOSR J Dent Med Sci. 2017;16(11):31-5.

13. Sujata P, Sahoo J, Rajkumari P, Sahoo G. Evaluation of obstetric near miss and maternal deaths in a tertiary care teaching hospital. Int J Recent Sci Res. 2016;7(2):9001-5.

Cite this article as: Das KK, Das SK, Das D. A prospective study on maternal near miss cases at a tertiary care hospital. Int J Reprod Contracept Obstet Gynecol 2020;9:300-4. 